Case Report

\title{
Effective and Efficient Correction of Severe Skeletal Class II Division 1 Malocclusion with Intermaxillary Elastics
}

\author{
Mohammed K. Badri \\ Department of Pedodontics \& Orthodontics, College of Dentistry, Taibah University, Madinah, Saudi Arabia \\ Correspondence should be addressed to Mohammed K. Badri; mbadri@taibahu.edu.sa
}

Received 17 December 2020; Revised 18 February 2021; Accepted 22 February 2021; Published 2 March 2021

Academic Editor: Khalid Zawawi

Copyright (c) 2021 Mohammed K. Badri. This is an open access article distributed under the Creative Commons Attribution License, which permits unrestricted use, distribution, and reproduction in any medium, provided the original work is properly cited.

\begin{abstract}
Treatment of Class II malocclusion accompanied with a skeletal discrepancy is challenging. The approach of correction depends on several factors such as the status and pattern of growth, severity of the malocclusion, and patient cooperation. This case report describes a successful management of a 12-year-old young adolescent boy that was presented with a Class II division 1 malocclusion with an underlying skeletal discrepancy in horizontal and vertical dimensions. Growth modification was achieved by means of bite opening and unlocking the mandible together with Class II elastics and mechanics. Treatment was highly effective and efficient by achieving all treatment goals within a period of 18 months.
\end{abstract}

\section{Introduction}

Class II dental malocclusion considered as the second most prevalent malocclusion after Class I, with a prevalence range of $13 \%-24 \%$ [1-5]. As described and categorized by Edward Angle more than a century ago, Class II division 1 malocclusion is characterized by distal occlusion of the lower first molars by at least a half cusp width in relation to upper first molars resulting in locking of the mandible in a distal position. Moreover, specific traits of this division were the protrusion of the upper incisors and interruption of the relation of upper and lower incisors by the lower lip $[6,7]$. Nevertheless, Class II malocclusion often accompanied by a skeletal discrepancy that could be caused by either a deficient mandible, excessive growth of maxilla, or a combination of both $[8,9]$.

Treatment approach and modality for Class II division 1 with an underlying skeletal problem depend on several factors that should be considered by the clinicians such as chronological age, growth potential, skeletal maturity, severity of the condition, and patient motivation and cooperation [10, 11]. The treatment options for growing patients with such malocclusion mainly based on growth modification on an exact time-frame taking advantage of the adolescent growth spurt. Failure to initiate proper treatment within the proper timing will lead to deviation of treatment option towards camouflage or even orthognathic surgery. Treating growing adolescents could involve the use of Class II elastics, headgear, or functional appliances in order to restrain further maxillary growth and promote favorable mandibular growth.

Several studies showed that over the long-term treatment results achieved with Class II elastics are similar or comparable to those achieved with functional appliances, given that treatment started at an appropriate timing [12-17]. Both Class II elastics and functional appliances contributed to correction of the malocclusion by skeletal and dental changes, but Class II elastics resulted in a more dentoalveolar modification [17-19]. Several dentofacial changes are associated with the use of Class II elastics such as maxillary retraction, mandibular protraction, increase of lower anterior facial height, clockwise rotation of the occlusal plane, retroclination of maxillary incisors, proclination of mandibular incisors, and forward movement and extrusion of mandibular molars [16-22]. Most of the effects of Class II elastics are favorable, but in order to control any unwanted side effects, a good case selection and application of appropriate biomechanics should be considered by the orthodontist. 

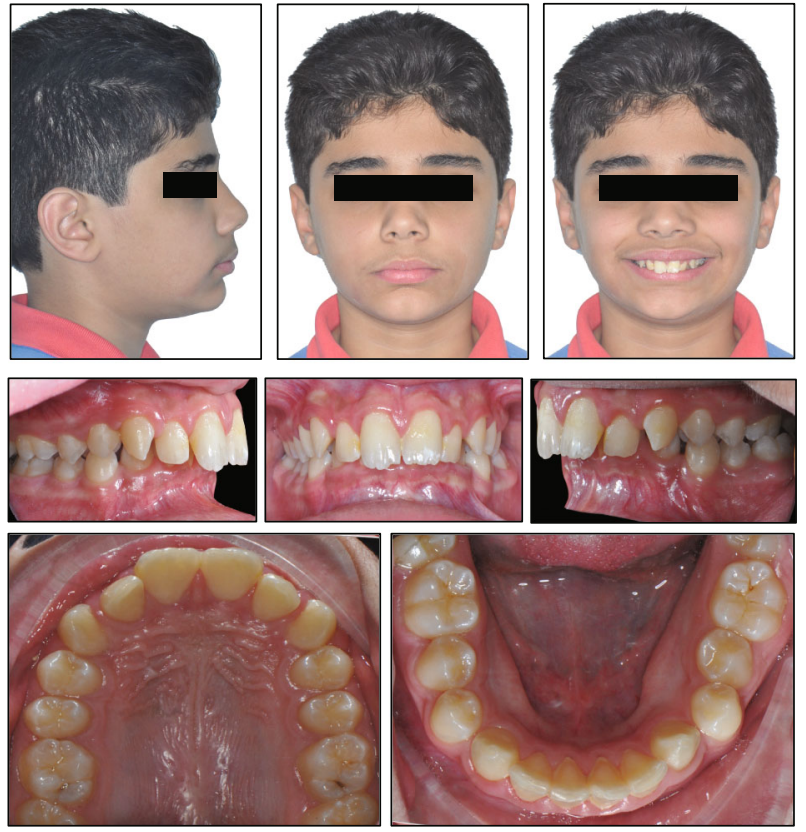

FIgURE 1: Pretreatment facial and intraoral photographs.

In the current case report, we discuss the treatment of a Class II division 1 malocclusion accompanied with a severe Class II skeletal discrepancy and hypodivergent growth pattern in a growing adolescent.

\section{Diagnosis and Etiology}

12 years and 8 months young boy referred to the orthodontic specialty clinic with a chief complaint of "protruded front teeth". Medical and dental history indicated no significant findings. Extraoral clinical examination revealed a symmetrical euryprosopic face type, convex soft tissue profile, retruded mandible, deep mentolabial sulcus, decreased lower facial third, and on smiling lower lip was trapped by the upper central incisors (Figure 1).

Intraoral and dental cast examination showed Class II division 1 malocclusion with full-step molars and canines bilaterally, severe overjet of $9 \mathrm{~mm}$, overerupted lower incisors with deep (100\%) impinging overbite, deep curve of Spee (COS) of $3 \mathrm{~mm}$, and unilateral posterior cross-bite on the upper left $1^{\text {st }}$ and $2^{\text {nd }}$ molars. Mild anterior crowding with rotated canines (uppers rotated disto-palatal and lowers rotated mesio-lingual). Patient had poor oral hygiene, plaque accumulation, and mild gingival inflammation. All permanent teeth are erupted while the $3^{\text {rd }}$ molars are still developing (Figures 1-3).

Cephalometric analysis revealed a severe skeletal Class II relationship $\left(\mathrm{ANB}=7.8^{\circ}\right)$ with horizontal growth pattern tendency (hypodivergent mandibular plane angle, MPA = $28.1^{\circ}, \mathrm{FMA}=19.6^{\circ}$ ), and anterior facial height is markedly reduced. Cervical vertebral maturation (CVM) indicates cervical stage 1 (CS1). Lower incisors are proclined $\left(\mathrm{L} 1-\mathrm{MP}=99.3^{\circ}\right)$, and both lips are anterior to the E-line by $1 \mathrm{~mm}$ (Figure 3 and Table 1 ).

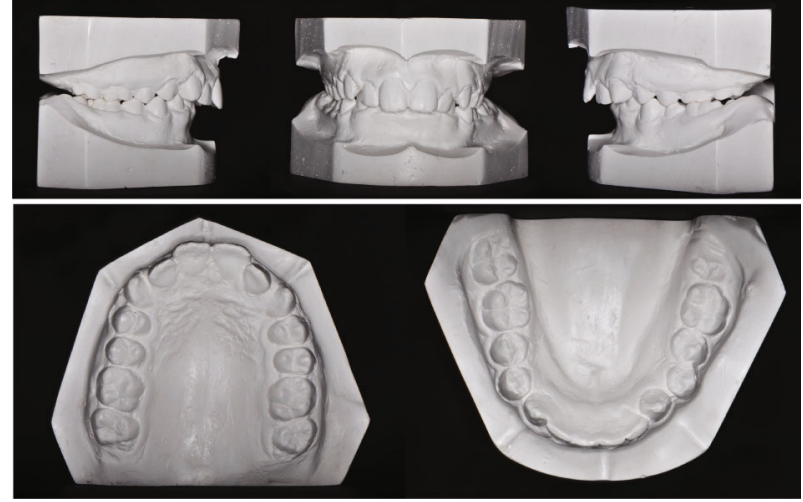

FIGURE 2: Pretreatment orthodontic study models.
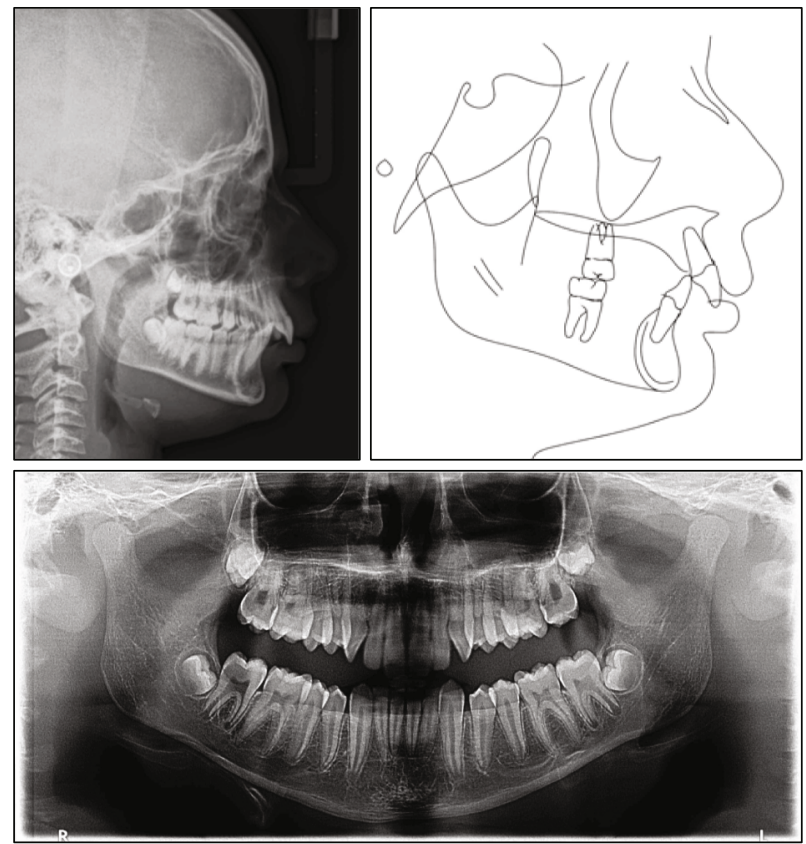

Figure 3: Pretreatment radiographs and tracing.

\section{Treatment Objectives}

The following were the list of treatment objectives: (1) improve the sagittal and vertical skeletal relationships; (2) enhance and guide mandibular growth; (3) resolve increased overjet; (4) establish Class I canine and molar relationship; (5) resolve the impinging overbite, deep COS, and traumatic occlusion; (6) resolve the left posterior cross bite; (7) resolve crowding and rotations; and (8) improve facial profile and smile esthetics.

\section{Treatment Alternatives}

Given the patient's age and problem list, a nonsurgical and nonextraction treatment plan based on growth modification to enhance mandibular growth was developed. The primary plan presented to the patient and his family was to start with growth modification using a removable Class II functional appliance or cervical pull headgear with anterior bite plane 
TABle 1: Cephalometric measurements.

\begin{tabular}{|c|c|c|c|c|}
\hline Measurement & Pretreatment & Posttreatment & 1-year follow-up & Norm \\
\hline \multicolumn{5}{|l|}{ Skeletal (sagittal) } \\
\hline SNA $\left({ }^{\circ}\right)$ & 85.8 & 81.5 & 82 & $82 \pm 3.5$ \\
\hline $\operatorname{SNB}\left({ }^{\circ}\right)$ & 78 & 76.7 & 77.5 & $80 \pm 3.5$ \\
\hline $\operatorname{ANB}\left({ }^{\circ}\right)$ & 7.8 & 4.8 & 4.5 & $2 \pm 2$ \\
\hline Wits (mm) & 5.6 & 0.4 & 1 & 5 \\
\hline Convexity (NA-APg) $\left({ }^{\circ}\right)$ & 12.9 & 6.9 & 6.2 & $0 \pm 5$ \\
\hline \multicolumn{5}{|l|}{ Skeletal (vertical) } \\
\hline SN-MP $\left(^{\circ}\right)$ & 28.1 & 31 & 30.8 & $32 \pm 5$ \\
\hline FMA $\left({ }^{\circ}\right)$ & 19.6 & 21.4 & 21.2 & $24 \pm 4.5$ \\
\hline$Y$-axis $(\mathrm{SGn} / \mathrm{SN})\left({ }^{\circ}\right)$ & 64.7 & 68.1 & 68 & $67 \pm 5.5$ \\
\hline \multicolumn{5}{|l|}{ Dental } \\
\hline $\mathrm{U} 1-\mathrm{SN}\left(^{\circ}\right)$ & 101.5 & 93.6 & 96.2 & $103 \pm 5.5$ \\
\hline U1-NA (mm) & 2.8 & 0.7 & 2 & $4.3 \pm 2.7$ \\
\hline Interincisal angle $\left({ }^{\circ}\right)$ & 132 & 123.6 & 127.6 & $130 \pm 6$ \\
\hline L1-MP $\left({ }^{\circ}\right)$ & 99.3 & 111.5 & 105.8 & $95 \pm 7$ \\
\hline L1-NB (mm) & 4.1 & 5.6 & 5.5 & $4 \pm 1.8$ \\
\hline \multicolumn{5}{|l|}{ Soft tissue } \\
\hline Nasolabial angle $\left(^{\circ}\right)$ & 118.2 & 111.7 & 116.6 & $102 \pm 8$ \\
\hline Upper lip to E-line (mm) & 0.8 & -1.8 & -1.2 & $-4 \pm 2$ \\
\hline Lower lip to E-line (mm) & 1.3 & -1.2 & -2.4 & $-2 \pm 2$ \\
\hline
\end{tabular}

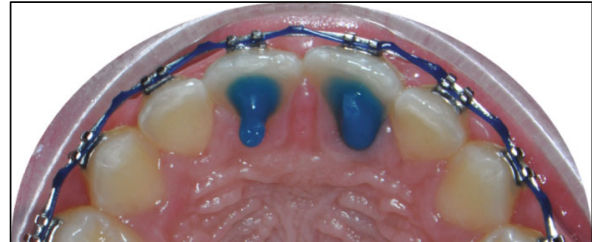

(a)

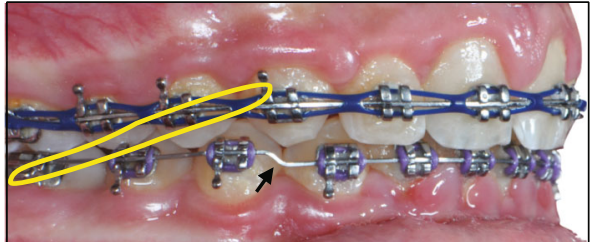

(b)

FIgURE 4: (a) Anterior bite turbo cemented on palatal of maxillary central incisors. (b) The use of reverse COS in the lower arch wire, step down bends (black arrow) for lower anterior teeth, and Class II elastic bands (yellow imaginary band).

followed by leveling and aligning with a fixed edgewise appliance. The option was not considered by the family due to increased cost from the use of additional device. In addition, the treatment duration could be prolonged especially if it was divided into two phases. Therefore, an alternative plan addressing those concerns was presented which involved bonding a fixed edgewise appliance, anterior bite turbo, and simultaneous growth modification using intermaxillary elastics taking advantage of the patient's early adolescence and prepubertal stage of development.

\section{Treatment Progress}

The patient demonstrated a poor oral hygiene and few carious lesions, so before starting orthodontic treatment, oral hygiene instructions were given, and patient was referred for periodontal and restorative clearance.
Once cleared, a full-fixed straight wire appliance of slot size $0.022^{\prime \prime} \times 0.028^{\prime \prime}$ MBT was bonded in both arches. Leveling and aligning lasted for 6 months, which were achieved by the following NiTi wire sequence $\left(0.014^{\prime \prime}, 0.016^{\prime \prime}, 0.018^{\prime \prime}\right.$, $\left.0.016^{\prime \prime} \times 0.022^{\prime \prime}\right)$ then followed by stainless steel (SS) working wires $\left(0.016^{\prime \prime} \times 0.022^{\prime \prime}, 0.018^{\prime \prime} \times 0.025^{\prime \prime}\right.$, and $0.019^{\prime \prime} \times$ $\left.0.025^{\prime \prime}\right)$. SS arch wire expansion and criss-cross elastic from palatal of upper left first molar to buccal of lower left molar were used to correct the unilateral posterior cross bite on left molars.

In addition, to address the vertical and sagittal skeletal problems, anterior bite turbos palatal to upper central incisors were cemented (Figure 4(a)); gradual step-down of lower anterior teeth (total of $3 \mathrm{~mm}$ ) and reverse curve of Spee were implemented by the lower SS arch wires (Figure 4(b)). Moreover, Class II intermaxillary elastics were started using light forces then replaced by medium force elastics as we progressed in treatment (Figure 4(b)). 

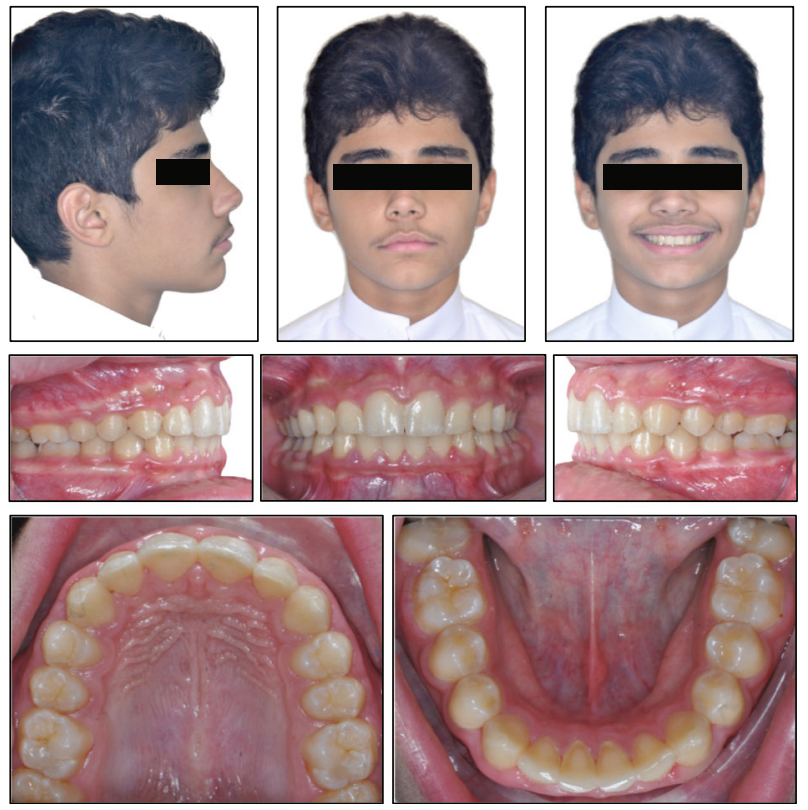

FIgURe 5: Posttreatment facial and intraoral photographs.

After 10 months in treatment, the antro-posterior canines and molars relationships were corrected. Final detailing and finishing included arch wire adjustments and power chain use for some remaining spaces closure. The fixed appliance was debonded after 18 months of active treatment. Clear vacuum retainers were delivered, and after 1 month, they were replaced by Hawley retainers with anterior bite plate on the upper appliance.

\section{Treatment Results}

The overall outcome of treatment was successful, and the patient's chief complaint was addressed. Treatment objectives were achieved in an efficient treatment duration (18 months and 14 visits). The skeletal and dental relationships were significantly improved. Facial profile showed great improvement as facial proportions were restored, mandible was advanced, convexity was reduced, and restored normal mentolabial sulcus. Moreover, smile esthetics were improved, and lip position was corrected with no entrapment (Figure 5). Intraoral photographs and dental models showed that Class I canine and molar were established both sides, normal overjet and overbite were achieved, and correction of deep COS and overerupted lower incisors. The unilateral posterior cross bite on left side molars was corrected with resulted increase in intermolar width of upper arch (Figures 5 and 6).

Lateral cephalometric analysis and superimposition showed significant skeletal improvement in sagittal and vertical dimensions with clockwise rotation of the mandible. Antro-posterior skeletal relationship changed from pretreatment (ANB 7.8 ${ }^{\circ}$, Wits $5.6 \mathrm{~mm}$ ) to posttreatment (ANB $4.8^{\circ}$, Wits $0.4 \mathrm{~mm}$ ), facial convexity decreased from $12.9^{\circ}$ to $6.9^{\circ}$, mandibular plane angle increased from (SN-MP 28.1 ${ }^{\circ}$, FMA $19.6^{\circ}$ ) to (SN-MP $31^{\circ}$, FMA $\left.21.4^{\circ}\right)$, total face height

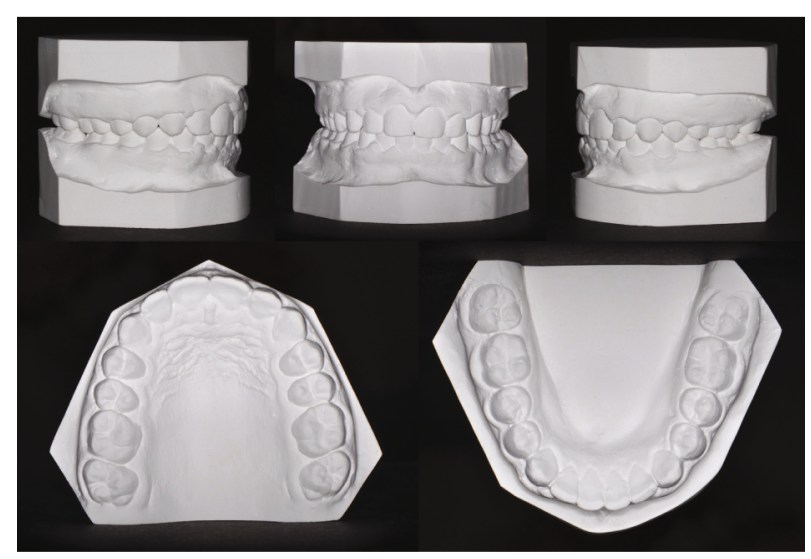

Figure 6: Posttreatment orthodontic study models.
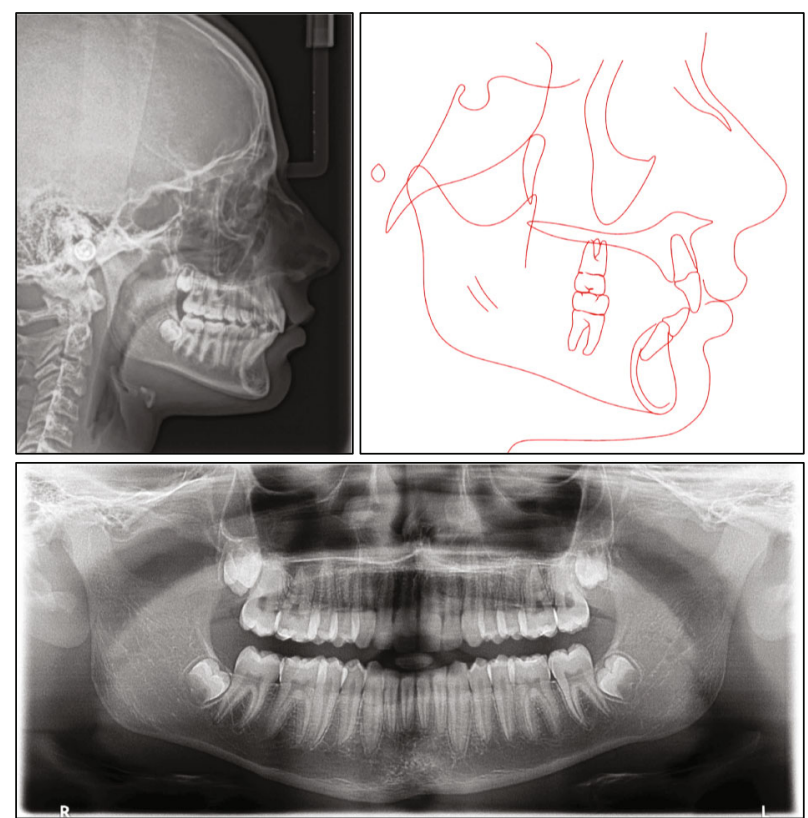

FIgURE 7: Posttreatment radiographs and tracing.

(Na-Gn) increased from $105.2 \mathrm{~mm}$ to $116.9 \mathrm{~mm}$, lower face height (ANS-Gn) increased from $59.7 \mathrm{~mm}$ to $65.5 \mathrm{~mm}$, and the hypodivergent growth pattern improved from $(y$-axis $\left.64.7^{\circ}\right)$ to $\left(y\right.$-axis $\left.68.1^{\circ}\right)$. Maxillary incisors were retroclined, and the deep bite was corrected by relative intrusion of a combination of molar extrusion and mandibular incisors intrusion and proclination. In addition, mandibular molars moved mesially while maxillary molars slightly distalized (Figures 7 and 8, Table 1).

At 1-year follow-up, the occlusion was stable with no significant relapse, and the patient demonstrated poor oral hygiene with mild gingival inflammation (Figure 9). Lateral cephalometric superimposition showed that both maxilla and mandible still growing in a favorable downward and forward direction and sagittal and vertical relations are maintained. Maxillary incisors slightly proclined while mandibular incisors slightly extruded, and its inclination to mandibular plane was improved (Figures 8 and 10, Table 1). 


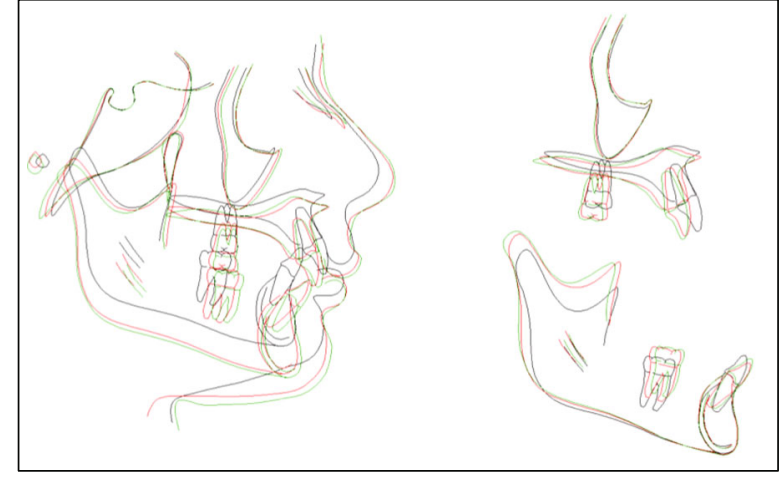

FIGURE 8: Superimposition of pretreatment (black), posttreatment (red), and follow up (green) lateral cephalograms.
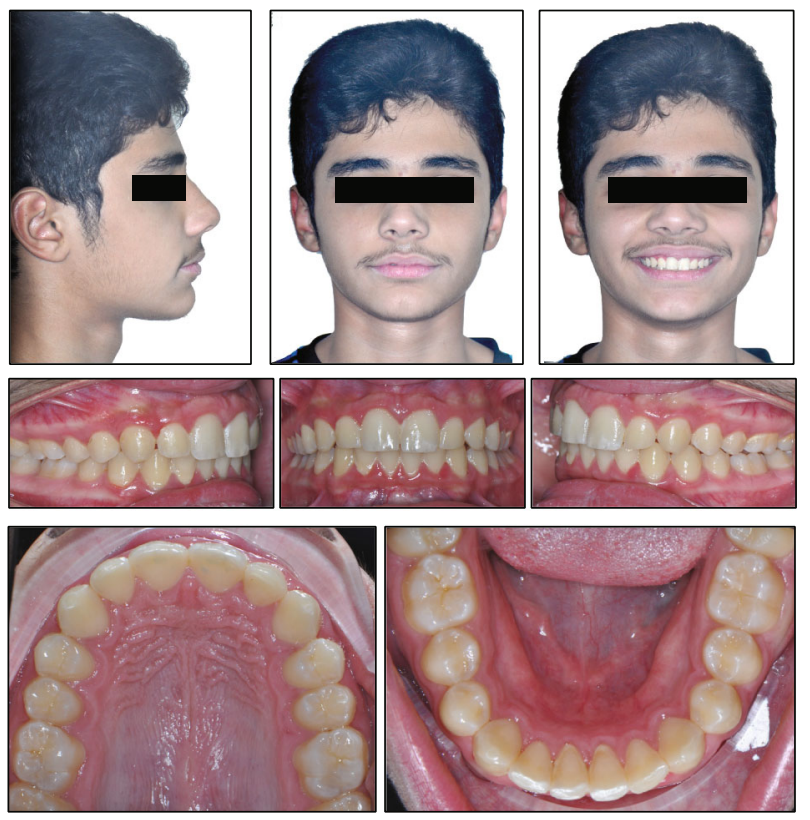

FIGURE 9: 1-year follow-up facial and intraoral photographs.

\section{Discussion}

This case report showed a successful management of a 12year-old adolescent boy presented with a Class II division 1 malocclusion accompanied with a severe skeletal Class II discrepancy. Several key factors contributed to the success of this treatment mainly including early intervention at prepubertal stage, pattern of skeletal growth, patient's cooperation, and mechanics applied.

The time of intervention in this case was of great impact in correcting the skeletal discrepancy. The treatment started when the patient was in the prepubertal stage of growth. The patient was at early stage of CVM (CS1, Figure 3), secondary sexual characteristics did not appear, and no significant increase in patient's height during the last 2 years, indicating that the growth spurt was yet to be hit. At posttreatment time point, the patient was in the postpubertal stage of maturity marked by the CVM (early CS4,
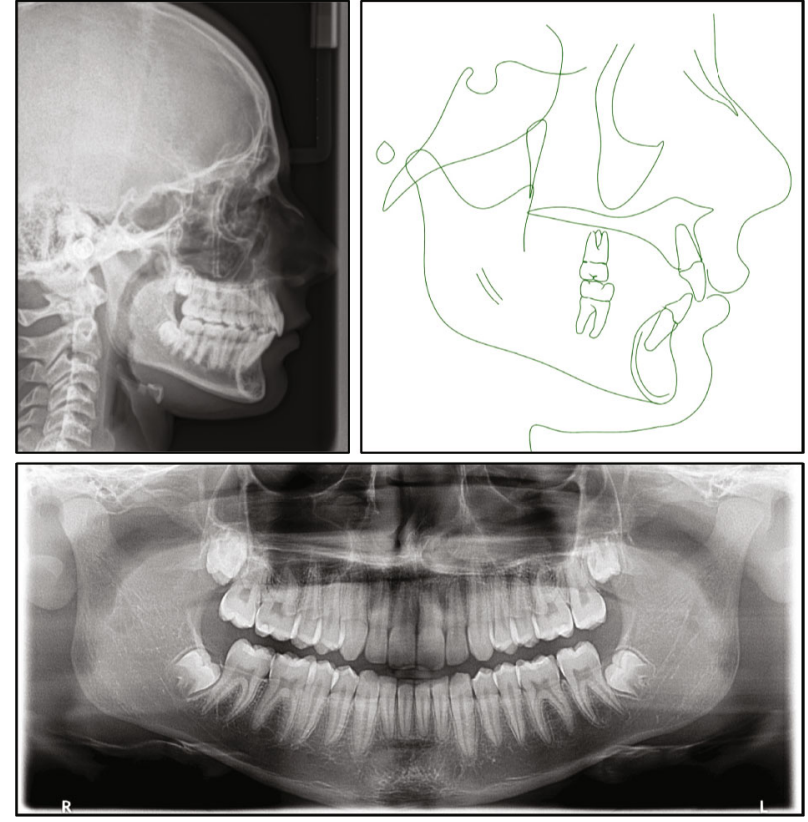

FIgURE 10: 1-year follow-up radiographs and tracing.

Figure 7), appearance of secondary sexual characteristics (such as facial hair and hoarse voice), and noticeable increase in height, thus indicating that growth spurt had hit during treatment. At the 1-year follow-up with a CVM of early CS5 (Figure 10), patient showed further mandibular growth with an increase of $2 \mathrm{~mm}$ in length; however, the mandibular growth spurt occurred during treatment with an increase of $6.7 \mathrm{~mm}$ (Co-Gn at pretreatment $=111.3 \mathrm{~mm}, \mathrm{Co}-\mathrm{Gn}$ at posttreatment $=118 \mathrm{~mm}$, Co-Gn at follow - up $=120 \mathrm{~mm}$ ). Cases of severe Class II skeletal problems are better to be treated as early as possible and to take advantage of the patient's growth spurt $[9,15]$. Moreover, regardless the type of intervention, the earlier the treatment, the greater the impact on mandibular growth [23] and the more stable the results are on the long term [15].

In the current case, upon opening the patient's bite and releasing the locked mandible from the impinging overbite, a great improvement in sagittal skeletal relation was achieved. Angle indicated that in Class II malocclusion, the lower dentition is locked in distal occlusion, and thereby, the mandible will be locked as well [6]. Several studies advocated that dental and occlusal interferences will restrict normal range of movement of the mandible by displacing it in a more posterior position and will hinder its normal growth [24-26]. Removal of such interferences by opening the bite will allow the mandible to shift forward, establish normal range of movement, reposition the condyles in the center of the fossae, and promote mandibular growth, thus reducing the sagittal skeletal discrepancy $[9,24-28]$. In a study of 60 patients with Class II deep bite of hypodivergent and normodivergent vertical relations, they showed great forward movement of the mandible with normal growth after bite opening [28].

It was well noticed that most of the sagittal discrepancy was improved after removing the restriction from the 
impinging deep bite and unlocking the mandible, while the use of Class II intermaxillary elastics was for a short period still effective to add to the final sagittal correction. Class II elastics carried out further guidance and enhancement of mandibular growth toward normal skeletal relation, added considerable restriction to the growth of the maxilla, and improved the vertical skeletal relationship (Table 1). Despite the correction of the sagittal skeletal problem and the increase in the mandibular body and ramus size, the patient did not show increase in the SNB angle (Table 1). This could be explained by the backward rotation of the occlusal plane and mandible from Class II elastics and mechanics used $[18,20,22]$. In hypodivergent growing patients, bite opening is achieved by incisors intrusion, molars eruption, or a combination of both. If the amount of molar extrusion overcame the amount of vertical condylar growth, a backward mandibular rotation will occur [27]. Therefore, a better reflection of the sagittal results will be using the Wits appraisal [29], and in this study, Wits improved significantly from $5.4 \mathrm{~mm}$ at pretreatment to $0.4 \mathrm{~mm}$ at posttreatment indicating Class I skeletal relationship (Table 1).

The vertical skeletal relationship improved significantly from the correction of the deep bite by use of reverse COS wires, Class II elastics, and bite turbos. Those mechanics helped to extrude the molars, intrude and procline the incisors, and facilitate further mandibular growth. As mentioned earlier, with Class II elastics, there is a clockwise rotation of the occlusal plane and mandible with a final outcome of increase in lower anterior face height [18, 20,22]. Such changes considered to be highly favorable in the current case which helped improve the hypodivergent vertical relationship.

The skeletal growth pattern of the patient was a favorable adjunct in the management of his case and helped in accommodating the current treatment plan. The vertically hypodivergent mandibular plane angle, the forward rotation of the mandible, and the underdeveloped anterior face height facilitated in toleration of the applied extrusive mechanics and the resulted backward rotation of the mandible. On the opposite, cases of vertical growth pattern with high mandibular plane angle are challenging and difficult to treat, and applying such extrusive mechanics should be avoided as they would deteriorate the final results and will not work in favor of the patients while more control of the vertical dimension should be considered [30].

Among the challenges that were faced in this case was to maximize the orthopedic changes using Class II elastics while minimizing elastics possible side effects. Proclination of lower incisors was significantly increased (Table 1) from Class II elastics, reserve wires use, and correction of deep COS. Such side effect could have been minimized if strict anchorage preparation was applied. Tweed advocated for rigorous anchorage preparation prior to the application of Class II elastics and mechanics in order to avoid proclination of anterior teeth [31]. In addition, Class II skeletal cases with excellent anchorage preparation prior to treatment showed greater orthopedic effects (such as maxillary retraction and mandibular protraction) comparing to cases treated with no anchorage preparation [21].

\section{Conclusion}

Class II elastics considered a viable orthodontic option for correcting Class II skeletal discrepancy in growing patients, given the careful case selection based on timing of growth spurt, pattern of skeletal development, severity of the malocclusion, and patient's cooperation and motivation.

Moreover, orthodontists should consider the benefits and potential side effects of Class II elastics use, plan that in the treatment, and be able to handle and direct them to the patient's favor once executed in treatment.

\section{Conflicts of Interest}

The authors declare that they have no conflicts of interest.

\section{References}

[1] S. Al-Emran and P. J. Wisth, "Prevalence of malocclusion and need for orthodontic treatment in Saudi Arabia," Community Dentistry and Oral Epidemiology, vol. 18, no. 5, pp. 253-255, 1990.

[2] W. R. Proffit, H. W. Fields Jr., and L. J. Moray, "Prevalence of malocclusion and orthodontic treatment need in the United States: estimates from the NHANES III survey," The International Journal of Adult Orthodontics and Orthognathic Surgery, vol. 13, no. 2, pp. 97-106, 1998.

[3] C. O. Onyeaso, G. A. Aderinokun, and M. O. Arowojolu, "The pattern of malocclusion among orthodontic patients seen in Dental Centre, University College Hospital, Ibadan, Nigeria," African Journal of Medicine and Medical Sciences, vol. 31, no. 3, pp. 207-211, 2002.

[4] M. O. Sayin and H. Türkkahraman, "Malocclusion and crowding in an orthodontically referred Turkish population," The Angle Orthodontist, vol. 74, no. 5, pp. 635-639, 2004.

[5] M. A. AlQarni, A. H. Banihuwaiz, F. D. Alshehri, A. S. Alqarni, and D. S. Alasmari, "Evaluate the malocclusion in subjects reporting for orthodontic treatment among Saudi population in Asser region," Journal of International Oral Health, vol. 6, no. 4, pp. 42-46, 2014.

[6] E. H. Angle, Treatment of Malocclusion of the Teeth: Angle's System, S.S. White dental manufacturing Company, Philadelphia, PA, USA, 7th edition, 1907.

[7] W. R. Proffit, H. W. Fields, B. E. Larson, and D. M. Sarver, Contemporary Orthodontics, Mosby Elsevier, St. Louis, MO, USA, 2019.

[8] R. E. Moyers, M. L. Riolo, K. E. Guire, R. L. Wainright, and F. L. Bookstein, "Differential diagnosis of class II malocclusions," American Journal of Orthodontics, vol. 78, no. 5, pp. 477-494, 1980.

[9] S. E. Bishara, "Class II malocclusions: diagnostic and clinical considerations with and without treatment," Seminars in Orthodontics, vol. 12, no. 1, pp. 11-24, 2006.

[10] W. R. Proffit, C. Phillips, J. F. Tulloch, and P. H. Medland, "Surgical versus orthodontic correction of skeletal class II malocclusion in adolescents: effects and indications," The International Journal of Adult Orthodontics and Orthognathic Surgery, vol. 7, no. 4, pp. 209-220, 1992.

[11] J. F. Camilla Tulloch, B. E. Lenz, and C. Phillips, "Surgical versus orthodontic correction for class II patients: age and 
severity in treatment planning and treatment outcome," Seminars in Orthodontics, vol. 5, no. 4, pp. 231-240, 1999.

[12] A. A. Gianelly, S. A. Arena, and L. Bernstein, "A comparison of class II treatment changes noted with the light wire, edgewise, and Fränkel appliances," American Journal of Orthodontics, vol. 86, no. 4, pp. 269-276, 1984.

[13] S. T. Adenwalla and J. H. Kronman, "Class II, division 1 treatment with Fränkel and Edgewise appliances-a comparative study of mandibular growth and facial esthetics," The Angle Orthodontist, vol. 55, no. 4, pp. 281-298, 1985.

[14] L. Weichbrodt and B. Ingervall, "Treatment of class II, div. 1 malocclusion with the activator and with the Begg technique," Schweizer Monatsschrift fur Zahnmedizin, vol. 102, no. 9, pp. 1037-1045, 1992.

[15] B. Nelson, U. Hägg, K. Hansen, and M. Bendeus, “A long-term follow-up study of class II malocclusion correction after treatment with class II elastics or fixed functional appliances," American Journal of Orthodontics and Dentofacial Orthopedics, vol. 132, no. 4, pp. 499-503, 2007.

[16] G. Jones, P. H. Buschang, K. B. Kim, and D. R. Oliver, "Class II non-extraction patients treated with the Forsus fatigue resistant device versus intermaxillary elastics," The Angle Orthodontist, vol. 78, no. 2, pp. 332-338, 2008.

[17] G. Janson, R. Sathler, T. M. F. Fernandes, N. C. C. Branco, and M. R. de Freitas, "Correction of class II malocclusion with class II elastics: a systematic review," American Journal of Orthodontics and Dentofacial Orthopedics, vol. 143, no. 3, pp. 383392, 2013.

[18] B. Nelson, K. Hansen, and U. Hägg, "Class II correction in patients treated with class II elastics and with fixed functional appliances: a comparative study," American Journal of Orthodontics and Dentofacial Orthopedics, vol. 118, no. 2, pp. 142149, 2000.

[19] S. Jayachandran, W. A. Wiltshire, S. M. Hayasaki, and F. H. S. L. Pinheiro, "Comparison of AdvanSync and intermaxillary elastics in the correction of class II malocclusions: a retrospective clinical study," American Journal of Orthodontics and Dentofacial Orthopedics, vol. 150, no. 6, pp. 979-988, 2016.

[20] C. M. Stewart, S. J. Chaconas, and A. A. Caputo, "Effects of intermaxillary elastic traction on orthodontic tooth movement," Journal of Oral Rehabilitation, vol. 5, no. 2, pp. 159166, 1978.

[21] A. E. Phelps, "A comparison of lower face changes," The Angle Orthodontist, vol. 48, no. 4, pp. 283-290, 1978.

[22] B. Zimmer and D. Nischwitz, "Therapeutic changes in the occlusal plane inclination using intermaxillary elastics," Journal of Orofacial Orthopedics, vol. 73, no. 5, pp. 377-386, 2012.

[23] T. Baccetti, L. Franchi, and J. A. McNamara, "The cervical vertebral maturation (CVM) method for the assessment of optimal treatment timing in dentofacial orthopedics," Seminars in Orthodontics, vol. 11, no. 3, pp. 119-129, 2005.

[24] L. S. Timmons, "Induced change in the anteroposterior relationship of the jaws," The Angle Orthodontist, vol. 42, no. 3, pp. 245-251, 1972.

[25] C. F. Gugino and I. Dus, "Unlocking orthodontic malocclusions: an interplay between form and function," Seminars in Orthodontics, vol. 4, no. 4, pp. 246-255, 1998.

[26] T. A. Sellke, "Zero base bioprogressive: unlocking the door to the future," Seminars in Orthodontics, vol. 4, no. 4, pp. 210218, 1998.
[27] R. I. Levin, "Deep bite treatment in relation to mandibular growth rotation," European Journal of Orthodontics, vol. 13, no. 2, pp. 86-94, 1991.

[28] M. G. Woods, "Sagittal mandibular changes with overbite correction in subjects with different mandibular growth directions: late mixed-dentition treatment effects," American Journal of Orthodontics and Dentofacial Orthopedics, vol. 133, no. 3, pp. 388-394, 2008.

[29] A. Jacobson, "The "Wits" appraisal of jaw disharmony. 1975," American Journal of Orthodontics and Dentofacial Orthopedics, vol. 124, no. 5, pp. 470-479, 2003.

[30] P. Cozza, A. Marino, and L. Franchi, "A nonsurgical approach to treatment of high-angle class II malocclusion," The Angle Orthodontist, vol. 78, no. 3, pp. 553-560, 2008.

[31] C. H. Tweed, "The application of the principles of the edgewise arch in the treatment of class II, division 1, malocclusion," The Angle Orthodontist, vol. 6, no. 3, pp. 198-208, 1936. 